NEUROLOGY AND MEDICINE

\title{
Neurology and the kidney
}

\author{
D J Burn, D Bates
}

\begin{abstract}
Renal failure is relatively common, but except in association with spina bifida or paraplegia it is unlikely to occur as a result of disease of the CNS. Renal failure, however, commonly affects the nervous system. The effects of kidney failure on the nervous system are more pronounced when failure is acute. In addition to the important problems related to renal failure there are both acquired and genetically determined diseases which may affect the kidney and the brain. Those acquired diseases include the vasculitides, the paraproteinaemias, and various granulomatous conditions (considered in other chapters of Neurology and Medicine). In two of the most commonly encountered genetically determined diseases, Von Hippel-Lindau disease and polycystic kidney disease, location of pathogenic mutations will provide improved screening programmes and, possibly, allow therapeutic intervention. Uraemia may affect both the central and peripheral nervous systems. Whereas the clinical features of uraemia are well documented, the pathophysiology is less well understood and probably multifactorial. Uraemic encephalopathy, which classically fluctuates, is associated with problems in cognition and memory and may progress to delirium, convulsions, and coma. The encephalopathy may initially worsen with periods of dialysis and almost certainly relates to altered metabolic states in association with ionic changes and possibly impaired synaptic function. Renal failure may affect the peripheral nervous system, resulting in a neuropathy which shows a predilection for large diameter axons. This may be reversed by dialysis and transplantation. The myopathy seen in renal failure, often associated with bone pain and tenderness, is similar to that encountered in primary hyperparathyroidism and osteomalacia.
\end{abstract}

Dialysis itself is associated with neurological syndromes including the dysequilibrium syndrome, subdural haematoma, and Wernicke's encephalopathy. Dialysis dementia, which was prevalent during the 1970s, has reduced in frequency with the use of aluminium free dialysate. With the introduction of transplantation and the concomitant use of powerful immunosuppressive drugs, the pattern of neurological problems encountered in renal replacement therapy has shifted. Five per cent of patients develop nerve injuries during renal transplantation, and up to $40 \%$ of patients experience neurological side effects from cyclosporine. Furthermore, CNS infections, often fungal in type, have been reported in up to $45 \%$ of transplant patients coming to postmortem. The nature of the involvement of neurologists with their nephrology colleagues is therefore evolving. (F Neurol Neurosurg Psychiatry 1998;65:810-821)

Keywords: Kidney

This review concentrates on recent developments in conditions which affect both the kidney and the nervous system, the effects of uraemia on the nervous system, and the neurological complications of dialysis and renal transplantation. The kidney receives about a quarter of the cardiac output. Its major functions are to regulate volume of body fluids, solutes, and $\mathrm{pH}$ and to concentrate the urine above plasma. The kidney also secretes renin and erythropoietin and has $1 \alpha$-hydroxylase activity. It is vital in the control of systemic blood pressure and the excretion of water soluble drugs and their metabolites. The effects of kidney failure on the nervous system are more pronounced when the failure is acute.

Genetically determined diseases affecting both the kidney and the nervous system VON HIPPEL-LINDAU DISEASE

Von Hippel-Lindau disease (VHL) is an autosomal dominant inherited disorder characterised by a predisposition to develop various tumours, most notably CNS haemangioblastomas and renal cell carcinoma (table 1). ${ }^{12}$ The prevalence of the condition has been estimated to be between $1 / 35000$ and $1 / 40000 .^{3}$ New mutations occur in only $1 \%-3 \%$ of cases of VHL. Incomplete penetrance is also probably rare. Apparent "obligate carriers" are affected but asymptomatic subjects when carefully screened. The VHL tumour suppressor gene was discovered by positional cloning in 1993 and its locus is chromosome 3p25-p26. Several mutations in this gene have been detected, but in about $20 \%$ of cases of VHL the 
Table 1 Proposed classification of von Hippel-Lindau disease (VHL) from the National Cancer Institute

\begin{tabular}{ll} 
Type & Clinical description \\
\hline I & $\begin{array}{l}\text { VHL without phaeochromocytoma: retinal and CNS haemangioblastoma, renal } \\
\text { cancers, and pancreatic involvement }\end{array}$ \\
II & $\begin{array}{l}\text { VHL with phaeochromocytoma: (A) plus retinal and CNS haemangioblastomas, (B). } \\
\text { plus retinal and CNS haemangioblastomas, renal cancers, and pancreatic involvement }\end{array}$
\end{tabular}

This classification is based on phenotype. Type I is the most common form. Type IIA is the next most common and has a milder clinical course. Type IIB is the most unusual phenotype of VHL.

mutation has not yet been identified. The disease is a classic example of the "two hit hypothesis" for tumorigenesis, in which a second mutation of the wild type allele in a susceptible tissue, in combination with the ubiquitous germ line mutation, leads to the development of carcinoma.

Retinal angiomas (more correctly termed haemangioblastomas, as the histology is identical to the lesions found in the CNS), are found in about $60 \%$ of patients with VHL. ${ }^{135}$ They are typically the earliest manifestation of the disease (mean age at diagnosis 25 years, range $1-67$ years). Retinal angiomas are bilateral in $50 \%$ of patients. Profound visual loss may occur via the complications of haemorrhage, retinal detachment, glaucoma, and cataract. Regular screening and aggressive treatment by laser photocoagulation are the mainstays of management.

Cerebellar haemangioblastomas occur in $50 \%-70 \%$ of cases of VHL, and may be asymptomatic in up to $50 \% .^{35}$ Mean age at diagnosis is 30 years (range $11-78$ years). The hemispheres are more commonly affected than the vermis, and the lesions may be multiple (fig 1). Mast cells are found within the lining epithelium of the cysts, and may be responsible for the production of erythropoietin, which can lead to erythrocytosis. The spinal cord, notably the craniocervical junction and conus medullaris, and brainstem are the two other sites of predilection for CNS haemangioblastomas. Syringomyelia or syringobulbia may complicate these lesions. ${ }^{3}$

Regular MRI of the whole neuroaxis with gadolinium enhancement is the mainstay of monitoring for CNS haemangioblastomas. ${ }^{2}$ Neurosurgery, where possible, and radiotherapy, including stereotactic radiosurgery, may be employed for identified lesions.

Renal cysts of all sizes may be present in $85 \%$ of cases of VHL. ${ }^{13}$ Renal cell carcinoma develops in between $24 \%$ and $45 \%$ of patients with VHL at a mean age of 37 years (range 16-67 years). The evolution of the cysts, and whether they represent a precursor for renal cell carcinoma or not is controversial. Renal involvement is multicentric and bilateral in over $75 \%$ of patients. The clinical presentation and the risk of metastasis is similar to that in sporadic non-familial renal cell carcinoma. ${ }^{1}$ Screening with both CT and ultrasound modalities is essential for the diagnosis of renal involvement in VHL. ${ }^{3}$ Multiple operations to carry out nephron sparing tumour removal may be necessary, occasionally culminating in bilateral nephrectomy. Renal transplantation

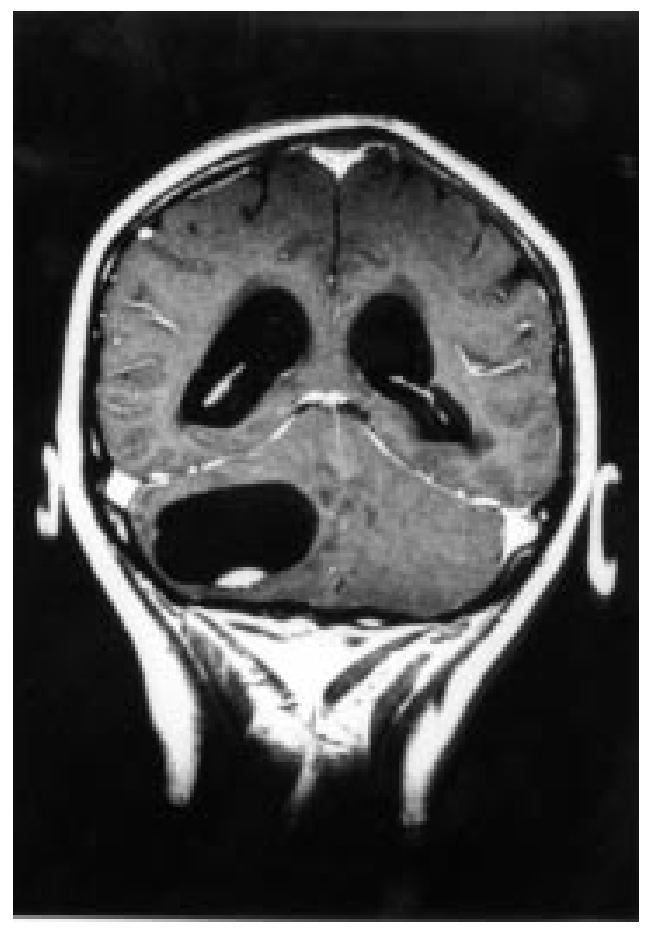

Figure $1 \quad T 1$ weighted gadolinium enhanced brain MRI; coronal section, through the posterior fossa showing cerebellar haemangioblastoma.

and the need for immunosuppression may then only serve to promote tumour growth elsewhere.

The location of a pathogenic mutation within the VHL gene in most families has been of great benefit in determining those who are genotypically affected, and who therefore require careful screening. In these patients, an annual array of clinical, imaging, ophthalmological, and biochemical techniques are necessary for the early detection of tumours. The mean age at death in VHL of 49 years quoted in earlier work may now be somewhat pessimistic because of improved screening and management programmes. The commonest causes of death are complications from cerebellar haemangioblastoma and metastatic renal cell carcinoma. An example of a screening protocol for VHL in affected patients and at risk relatives is shown in table 2 .

POLYCYSTIC KIDNEY DISEASE

Polycystic kidney disease (PCKD) is a genetically heterogeneous disease that may exist in both autosomal dominant and recessive forms. The second form is one of the most common hereditary cystic diseases in children, with most cases presenting in infancy. ${ }^{6}$ The gene has been mapped to the chromosomal 6p21-cen region. ${ }^{7}$ Autosomal dominant polycystic kidney disease (ADPKD) exists in at least three distinct forms: In about $86 \%$ of affected European families the affected gene (PKD1) has been localised to chromosome 16p13.3, and in the remaining $14 \%$ a second locus (PKD2) has recently been found on chromosome 4q13-q23 and a third (PKD3) is so far unlinked. ${ }^{8}{ }^{9}$ Mutations at the PKD1 locus are associated with a more severe clinical phenotype, with higher risk 
Affected patient:

(1) Annual physical examination and urine testing

(2) Annual direct and indirect ophthalmoscopy with fluoroscein angioscopy or angiography

(3) Brain MRI every 3 years to age 50 and every 5 years thereafter

(4) Annual renal ultrasound scan, with CT scan every 3 years (more frequently if multiple renal cysts present)

(5) Annual 24 hour urine collection for VMA* or metanephrines

At risk relative:

(1) Annual physical examination and urine testing

(2) Annual direct and indirect ophthalmoscopy from age 5. Annual fluoroscein angioscopy or angiography from age 10 until age 60

(3) Brain MRI every 3 years from age 15 to 40 years then every 5 years until age 60 years

(4) Annual renal ultrasound scan, with abdominal CT every 3 years from age 20 to 65 years

(5) Annual 24 hour urine collection for VMA or metanephrines

* VMA=vanillylmandelic acid.

These guidelines are for asymptomatic subjects; symptomatic patients require urgent investigation. With the advent of genetic testing, the frequency of screening of at risk relatives may be significantly reduced.

of progression to renal failure, higher incidence of hypertension, and earlier age of death than the PKD2 variant. ${ }^{10}$ PKD1 has been fully sequenced and the protein which it encodes has been called polycystin. This is a membrane glycoprotein with multiple transmembrane domains which is expressed particularly in renal epithelial cells. Its function is as yet uncertain but it may mediate cell-cell or cell-matrix interactions, or possibly act as an ion channel regulator. Interestingly, PKD1 gene expression seems highest in the brain. ${ }^{9}$ Even within patients with PKD1 mutations there is marked phenotypic heterogeneity, but no clear genotype-phenotype correlation has emerged so far.

The clinical presentation of adult PCKD may be at any age from the second decade. Presenting symptoms include acute loin pain or haematuria due to haemorrhage into a cyst, vague loin or abdominal discomfort due to the increasing size of the kidneys, or symptoms of uraemia.

The most frequent and feared neurological complication of PCKD is intracranial haemorrhage from a ruptured arterial aneurysm. The prevalence of intracranial aneurysm in PCKD varies from $4 \%$ to $40 \%$ in different studies. ${ }^{11-13}$ The variability may in part depend on whether there is a positive family history for aneurysm and the investigational technique employed. The higher estimate is at variance with most data and the true figure is probably nearer 5\% to $15 \%$. The pathogenic association between the renal disease and intracranial aneurysm is unknown. Lozano and Leblanc, in a retrospective study, compared the clinical characteristics of ruptured intracranial aneurysm associated with PCKD in 79 patients with those from a cooperative study of sporadic aneurysms. ${ }^{14}$ Sixty eight patients had a single aneurysm, whereas in 11 there were multiple aneurysms. In patients with PCKC with subarachnoid haemorrhage from a single aneurysm there was an excess of males $(72 \%, \mathrm{p}<0.01)$ and more aneurysms of the middle cerebral artery $(37 \%$, $\mathrm{p}<0.05)$. Mean age of aneurysms associated with PCKD was younger (mean age 39.7 years), and over $77 \%$ of PCKD associated aneurysms had ruptured by the age of 50 , compared with $42 \%$ for sporadic aneurysms. Aneurysms associated with PCKD occurred irrespective of whether the patient was hypertensive or not.
Much uncertainty exists regarding the type of screening programmes needed for intracranial aneurysms in patients with PCKD. ${ }^{11}$ The advent of MR angiography, with a sensitivity of about $85 \%$ and specificity in the order of $90 \%$ in comparison with the potentially hazardous conventional catheter angiography has added a new non-invasive dimension to the screening equation. It would seem reasonable in patients with a high risk of intracranial aneurysms to recommend screening with $M R$ angiography at 2 to 3 yearly intervals, although the current National Institute of Health trial of management of asymptomatic aneurysms may provide better information on which to base a future screening programme.

In a series of 900 consecutive patients with haemorrhagic stroke from Taiwan 11 patients $(1.2 \%)$ had intracranial haemorrhage associated with PCKD. ${ }^{15}$ Eight had hypertensive cerebral haemorrhage and the other three had aneurysmal subarachnoid haemorrhage. Hypertension had been inadequately treated or not even recognised in the eight patients, illustrating that not all intracranial haemorrhages in PCKD are aneurysmal in origin, and that rigorous management of hypertension is also important.

Arachnoid cysts may be more prevalent in PCKD (5.2-7.5\%), compared with age and sex matched controls $(1 \%) .{ }^{11}$ Single case reports have also indicated associations of PCKD with eosinophilic granuloma and moyamoya disease ${ }^{16}$ and with familial amyloidosis, sensory and motor polyneuropathy, and vitreous opacities. ${ }^{17}$ It is also associated with a higher prevalence of mitral and aortic valve incompetence, and mitral valve prolapse. ${ }^{18}$ Such abnormalities should be borne in mind in the event of a thromboembolic stroke in a patient with PCKD.

\section{WILSON'S DISEASE}

This autosomal recessive condition is due to an abnormal gene (ATP7B) on chromosome 13q14.3 which codes for a defective copper transporting ATPase. In most European countries the prevalence of Wilson's disease at birth is $12-18 /$ million. The neurological and hepatic involvement of Wilson's disease are well known, with about $40 \%$ of patients presenting with hepatic disease (acute or chronic hepatitis, cirrhosis, or acute liver failure) and $40 \%$ with neurological problems (tremors, dystonia, 
dysarthria, drooling, or gait disturbance dominate initially). ${ }^{19}$

Disturbance of renal function is assumed to occur from the toxic effects of accumulated copper. Symptoms referrable to the kidneys are uncommon in Wilson's disease but haematuria and nephrolithiasis are reported. Severe dysfunction of the proximal tubules may produce a Fanconi syndrome, resulting in generalised aminoaciduria, glycosuria, salt wasting, hypercalciuria, hypophosphataemia, acidosis, hypouricaemia, and tubular proteinuria.

In patients with chronic liver disease the hepatorenal syndrome may occur. In this syndrome the urine output is low with a low urinary sodium concentration, a residual capacity to concentrate urine (tubular function is intact), and almost normal renal histology. Advanced cases may progress to acute tubular necrosis. The pathophysiology of the hepatorenal syndrome may involve reduced medullary prostaglandin $\mathrm{H}$ synthase activity.

The treatment of Wilson's disease with D-penicillamine may lead to an immune complex nephropathy in 5\%-10\% of patients. ${ }^{19}$

FABRY'S DISEASE

This is an $\mathrm{X}$ linked inborn error of metabolism caused by a deficiency of the enzyme $\alpha$-galactosidase A (ceramide trihexosidase). This leads to the accumulation of glycosphingolipids, especially in blood vessel walls, ganglion cells, kidney, eyes, and heart. The condition becomes evident in late childhood or adolescence. The principle neurological symptoms are of recurrent lancinating or burning pain in the limbs, with acral paraesthesia. Dysautonomia and a low grade fever may also occur.

Signs of renal dysfunction may occur in late childhood, but severe renal insufficiency and hypertension do not develop until adulthood. Lipid laden cells may be found in the urine sediment. Death usually occurs in the fifth decade, due to uraemia or cerebrovascular disease. Renal transplantation has been used to treat the renal failure, but does not provide enough enzyme replacement to cure the disease. ${ }^{20}$

\section{Acquired diseases affecting both the kidney and the nervous system}

Vasculitides, paraproteinaemias, and granulomatous conditions, by their nature, involve more than one organ system and several present with both renal and neurological syndromes. ${ }^{21} 22$ The syndromes are dealt with in other papers in the current series of Neurology and Medicine, and are therefore only summarised in table 3 .

\section{The effects of uraemia on the nervous system \\ CENTRAL MANIFESTATIONS}

Uraemic encephalopathy

Uraemic encephalopathy is an organic brain syndrome which occurs in patients with untreated renal failure and in association with dialysis. The encephalopathy is usually more severe and progresses more rapidly in patients with an acute deterioration in renal function. The clinical course is characterised by variability from day to day, or even hour to hour. Early symptoms may be subtle, and comprise fatigue, apathy, clumsiness, and impaired concentration. Tests of attention span are often impaired at this stage. ${ }^{23-27}$

As the encephalopathy worsens, the patient may become emotionally labile, more obviously forgetful and sluggish, make perceptual errors, and develop sleep inversion. "Frontal lobe" symptoms are manifest by impaired abstract thinking and behavioural change. Paratonia (Gegenhalten, an involuntary and variable resistance to passive movement), grasp, and palmomental reflexes provide further evidence of frontal lobe dysfunction.

In the late stages of uraemic encephalopathy the patient may be delirious, with visual hallucinations, disorientation, and agitation which evolve into torpor, preterminal coma, and convulsions. The last are usually generalised tonicclonic in type, although focal motor seizures are also common. Meningism may be elicited in about a third of patients. Multifocal myoclonus and asterixis (a form of negative myoclonus, derived from the Greek sterigma, which means without support, as well as a coarse postural and kinetic tremor characterise of the later stages of the encephalopathy. Limb tone is usually increased in uraemic coma, with hyperreflexia, ankle clonus, and extensor plantar responses. The signs may be asymmetric, with frank hemiparesis occurring in up to $45 \%$ of patients. These signs may alternate sides during the course of the illness (so called "alternating hemiparesis"). ${ }^{26}$

Even in patients who have been treated with renal replacement therapy, sluggishness, memory impairment, and sleep disturbances are not uncommon and may lead to impaired quality of life. Neuropsychological studies have compared the effectiveness of chronic haemodialysis and continuous ambulatory peritoneal dialysis regimens on these symptoms. Patients receiving either form of replacement therapy show significant deviations from normal controls in areas of attention/response speed, learning and memory, and perceptual coding. Choice reaction time, which measures sustained attention as well as speed of decision making, may be the most useful test to determine subtle cognitive impairment in uraemia. ${ }^{26}$ The method of dialysis seems to make little or no difference to the neuropsychological variables tested.

\section{Investigation of uraemic encephalopathy}

The level of azotaemia correlates poorly with the degree of neurological dysfunction. Laboratory blood tests therefore confirm that the patient has renal impairment, but do not exclude other causes for the encephalopathy, and provide little help in monitoring neurological progress. ${ }^{26}$ Analysis of CSF in the uraemic patient with meningism may disclose an aseptic meningitis, with up to 250 lymphocytes and polymorphonuclear leucocytes $/ \mathrm{mm}^{3}$. The CSF protein may also be increased up to $1.0 \mathrm{~g} / 1 .^{27}$ 
Table 3 The renal and neurological complications of the vasculitides, paraproteinaemias, and granulomatous conditions

\begin{tabular}{|c|c|c|c|}
\hline Disease & Pathological features & Renal & Neurological \\
\hline \multicolumn{4}{|l|}{ Vasculitides: } \\
\hline \multicolumn{4}{|l|}{ Primary } \\
\hline Polyarteritis nodosa & $\begin{array}{l}\text { Necrotising vasculitis of medium and small } \\
\text { vessels }\end{array}$ & $\begin{array}{l}70 \% \text { show proteinuria and granular } \\
\text { casts progressing to renal failure. } 50 \% \\
\text { have hypertension }\end{array}$ & $\begin{array}{l}60 \% \text { have peripheral neuropathy - most } \\
\text { commonly painful mononeuropathy. } 40 \% \\
\text { have CNS involvement with } \\
\text { encephalopathy, focal infarction, } \\
\text { subarachnoid haemorrhage, seizures and } \\
\text { cranial neuropathies }\end{array}$ \\
\hline Churg-Strauss angiitis & $\begin{array}{l}\text { Eosinophilic necrotising vaculitis of medium } \\
\text { and small vessels, peripheral eosinophilia }\end{array}$ & $\begin{array}{l}\text { Infrequent renal involvement, rarely } \\
\text { granular casts and hypertension }\end{array}$ & $\begin{array}{l}\text { Mononeuropathy multiplex in } 75 \% \text {. } \\
\text { Central nervous system involvement in } \\
15-20 \% \text { manifesting as encephalopathy, } \\
\text { subarachnoid haemorrhage, rarely chorea }\end{array}$ \\
\hline Wegener's granulomatosis & $\begin{array}{l}\text { Necrotising granulomatous vasculitis } \\
\text { affecting respiratory tract and small vessels. } \\
\text { Crescentic glomerulonephritis }\end{array}$ & $\begin{array}{l}\text { Proteinuria, haematuria, red blood } \\
\text { cell casts, culminating in renal failure }\end{array}$ & $\begin{array}{l}\text { Cranial neuropathies due to local erosion } \\
\text { by sinus granuloma. Multiple } \\
\text { mononeuropathy and polyneuropathy, } \\
\text { rarely focal CNS ischaemia }\end{array}$ \\
\hline \multicolumn{4}{|r|}{  } \\
\hline Infections & $\begin{array}{l}\text { Bacterial and viral eg hepatitis B associated } \\
\text { PAN }\end{array}$ & & \\
\hline Toxins & Commonly in relation to illicit drug use & $\begin{array}{l}\text { Proteinuria, granular casts } \\
\text { culminating in renal failure }\end{array}$ & $\begin{array}{l}\text { Encephalopathy, focal infarction in the } \\
\text { central nervous system, mononeuropathy }\end{array}$ \\
\hline Neoplasia & Commonly lymphoid malignancy & & \\
\hline \multicolumn{4}{|l|}{ Connective tissue diseases: } \\
\hline Rheumatoid arthritis & $\begin{array}{l}\text { Polyarthritis with synovial hypertrophy. } \\
\text { Vasculitis of small and medium sized } \\
\text { arteries }\end{array}$ & $\begin{array}{l}\text { Rarely glomerulonephritis. Possible } \\
\text { association with amyloidosis }\end{array}$ & $\begin{array}{l}\text { Sensory or sensory motor peripheral } \\
\text { neuropathy. Rarely mononeuropathy. Rare } \\
\text { ischaemic central nervous system damage. } \\
\text { Cranio-vertebral junction and high } \\
\text { cervical cerd lesions in association with } \\
\text { atlantoaxial subluxation and pannus } \\
\text { formation }\end{array}$ \\
\hline $\begin{array}{l}\text { Systemic lupus } \\
\text { erythematosus }\end{array}$ & $\begin{array}{l}\text { Immune complex deposition and direct } \\
\text { autoantibody effects }\end{array}$ & $\begin{array}{l}\text { Haematuria, proteinuria, nephrotic } \\
\text { syndrome, renal failure }\end{array}$ & $\begin{array}{l}\text { Encephalopathy in } 40 \% \text { including } \\
\text { neuropsychiatric and behavioural } \\
\text { abnormalities. Seizures as presenting } \\
\text { symptom in } 5 \% \text {. Cerebrovascular } \\
\text { accidents, chorea, cranial neuropathies. } \\
\text { Rarely distal sensory or sensory motor } \\
\text { neuropathy and occasionally chronic } \\
\text { inflammatory demyelinating } \\
\text { polyneuropathy }\end{array}$ \\
\hline Sjögren's disease & $\begin{array}{l}\text { Commonly presence of anti-Ro and anti-La } \\
\text { antibodies }\end{array}$ & $\begin{array}{l}\text { Lymphoid infiltration, tubular } \\
\text { disorders and failure of acidification } \\
\text { of urine }\end{array}$ & $\begin{array}{l}\text { Peripheral neuropathy. Dorsal root } \\
\text { ganglioneuropathy. Autonomic } \\
\text { neuropathy. Cranial neuropathy seen in } \\
40 \% \text {. Psychiatric disorders and focal } \\
\text { central nervous system disturbances which } \\
\text { may mimic multiple sclerosis }\end{array}$ \\
\hline \multicolumn{4}{|l|}{ Plasma cell dyscrasias } \\
\hline Multiple myeloma & $\begin{array}{l}\text { Tissue infiltration with plasma cells. Direct } \\
\text { effect of antibodies }\end{array}$ & $\begin{array}{l}\text { Proteinuria (Bence-Jones), nephrotic } \\
\text { syndrome, chronic renal failure }\end{array}$ & $\begin{array}{l}\text { Nerve root and spinal cord compression. } \\
\text { Intracranial cerebral and cranial nerve } \\
\text { compression. Peripheral neuropathy - } \\
\text { relatively rare, usually axonal and } \\
\text { sensorimotor }\end{array}$ \\
\hline $\begin{array}{l}\text { POEMS (Osteosclerotic } \\
\text { myeloma) }\end{array}$ & $\begin{array}{l}\text { Binding of immunoglobulins to neural } \\
\text { components. Cytokine effects }\end{array}$ & $\begin{array}{l}\text { M-protein rarely discovered in urine. } \\
\text { Proteinuria uncommon. } \\
\text { Haemangiomas may occur in the } \\
\text { kidney }\end{array}$ & $\begin{array}{l}50 \% \text { of patients have predominantly } \\
\text { motor neuropathy resembling chronic } \\
\text { inflammatory demyelinating } \\
\text { polyneuropathy (CIDP) }\end{array}$ \\
\hline $\begin{array}{l}\text { Monoclonal gammopathies } \\
\text { of unknown significance } \\
\text { (MGUS) }\end{array}$ & $\begin{array}{l}\text { Associated with lymphoid and } \\
\text { non-lymphoid neoplasia and other } \\
\text { autoimmune conditions. Probably affects } \\
3 \% \text { of the population }\end{array}$ & $\begin{array}{l}\text { Rarely significant abnormality. } \\
\text { Occasionally proteinuria and rarely } \\
\text { amyloid deposition }\end{array}$ & $\begin{array}{l}\text { Progressive sensory }>\text { motor } \\
\text { demyelinating neuropathy (IgM), CIDP }\end{array}$ \\
\hline $\begin{array}{l}\text { Waldenström's } \\
\text { macroglobulinaemia }\end{array}$ & $\begin{array}{l}\text { Uncontrolled proliferation of lymphcytes } \\
\text { and plasma cells }\end{array}$ & $\begin{array}{l}\text { Proteinuria, nephrotic syndrome and } \\
\text { renal failure }\end{array}$ & $\begin{array}{l}\text { Slowly progressive sensory and motor } \\
\text { neuropathy. Encephalopathy due to } \\
\text { hyperviscosity syndrome. Myelopathy, } \\
\text { cerebrovascular accidents and } \\
\text { subarachnoid haemorrhage }\end{array}$ \\
\hline \multicolumn{4}{|l|}{ Cryoglobulinaemia } \\
\hline $\begin{array}{l}\text { Type } 1 \text { (single monoclonal } \\
\text { protein) }\end{array}$ & $\begin{array}{l}\text { Waldenström's macroglobulinaemia, } \\
\text { multiple myeloma, lymphoproliferative } \\
\text { disease }\end{array}$ & See above & See above \\
\hline $\begin{array}{l}\text { Type } 2 \text { (monoclonal IgM } \\
\text { rheumatoid factor and } \\
\text { polyclonal IgG) }\end{array}$ & Chronic infections. & $\begin{array}{l}\text { Renal failure (glomerulonephritis), } \\
\text { nephrotic syndrome }\end{array}$ & $\begin{array}{l}\text { Multiple mononeuropathy, sensory and } \\
\text { motor neuropathy in } 7 \% \text {. Transient } \\
\text { ischaemic attacks, cerebral infarction }\end{array}$ \\
\hline $\begin{array}{l}\text { Type } 3 \text { ( polyclonal IgM } \\
\text { rheumatoid factor and } \\
\text { polyclonal IgG) }\end{array}$ & $\begin{array}{l}\text { Chronic inflammatory or infective processes. } \\
\text { Mixed essential cryoglobulinaemia }\end{array}$ & & \\
\hline
\end{tabular}

Cerebral imaging with CT or MRI is usually unhelpful, although it will exclude other causes of confusion, such as subdural haematoma or hydrocephalus. Chronic renal impairment may be associated with cerebral atrophy. Reversible signal changes (low signal intensity on $\mathrm{T} 1$ weighted and high signal on T2 weighted images) in the basal ganglia, periventricular white matter, and internal capsule have been described on MRI in chronic uraemic encephalopathy; the lesions disappear after dialysis. ${ }^{28}$ They are of uncertain relevance and have not been widely reported.

The EEG is usually most abnormal in the acute encephalopathic state, within 48 hours of the onset of renal failure. There is a generalised slowing of the EEG, most marked frontally, with an excess of delta and theta waves. In 
chronic renal failure the changes are less dramatic. As the uraemic state progresses, the EEG becomes slower, with a reasonable correlation between the percentage of frequencies below $7 \mathrm{~Hz}$ and the increase in serum creatinine. ${ }^{24}$ Bilateral spike and wave complexes, in the absence of evident clinical seizure activity, have been reported in up to $14 \%$ of patients with chronic renal failure.

Pathophysiology of uraemic encephalopathy The pathophysiology of uraemic encephalopathy is uncertain. Changes found in the brain of patients dying with chronic renal impairment are often mild, non-specific, and relate more to concomitant illnesses. ${ }^{24}$ The calcium content of the cerebral cortex is almost twice that of the normal value. This increase may be mediated by parathyroid hormone activity, an effect probably independent of cyclic AMP. In dogs with experimentally induced acute or chronic renal failure, both EEG and brain calcium abnormalities may be prevented by parathyroidectomy. ${ }^{29}$ In humans with renal failure, both EEG and psychological abnormalities may be improved after parathyroidectomy. ${ }^{30}$

In renal impairment, the metabolic rate of the brain is reduced and this is, in turn, associated with a decrease in cerebral oxygen consumption. These changes occur despite normal concentrations of high energy phosphates. One possible explanation for these changes would be a reduction in neurotransmission, leading to a reduction in metabolic activity. Synaptosomal preparations include vesicles derived from presynaptic terminals and allow the activities of the sodium/calcium exchanger and calcium ATPase pumps to be studied. These two pumps export calcium from excitable cells and are important in maintaining the calcium gradient of $10000: 1$ (outside-inside cells) which normally exists. In the presence of uraemia, there is a PTH dependent enhancement of calcium transport by both transporter mechanisms. Some studies have suggested that the ouabain sensitive sodium/potassium ATPase pump activity is decreased in both acute and chronic uraemic states. ${ }^{24}$ As this pump is ultimately important in the release of neurotransmitters such as the biogenic amines, this could help to explain impaired synaptic function and reduction in the concentration of neurotransmitters which have been found in uraemic rats.

Further evidence of impaired synaptic function in uraemia comes from studies of the inhibitory effects of guanidino compounds, especially guanidinosuccinic acid, on the release of $\gamma$-aminobutyric acid (GABA) and glycine in animal models. These toxins, which are raised in brain and CSF in renal failure, probably impair the release of neurotransmitters by blocking neuronal membrane chloride channels. In addition, methylguanidine has been shown to inhibit sodium/potassium ATPase pump activity.

Finally, the role of aluminium in chronic uraemic encephalopathy is still uncertain. The source of the metal is likely to be from diet and phosphate binding drugs. ${ }^{31}$ Transport of aluminium into the brain almost certainly occurs via transferrin receptors on the luminal surface of brain capillary endothelial cells. Once in the brain the aluminium may affect the expression or processing of the $\beta \mathrm{A} 4$ precursor protein which, via a complex cascade of events, may lead to extracellular deposition of amyloidogenic $\beta A 4$ protein in senile plaques. It is unlikely, however, that the pathology so induced merely represents an Alzheimer-like change, as neurofibrillary tangles, which characterise Alzheimer's disease, are not commonly found in the cerebral cortex of patients undergoing renal dialysis. ${ }^{32}$

To summarise, the pathophysiology of uraemic encephalopathy is a complex and probably multifactorial process. Initial problems reflect a functional, primarily neurotransmission defect. Subsequent dysfunction may be due to increasingly evident histopathological change, and aluminium could be of key importance in this process.

\section{PERIPHERAL MANIFESTATIONS}

\section{Uraemic neuropathy}

This complication was probably first reported in 1863 by Kussmaul (cited in Jennekens ${ }^{33}$ ). Neuropathy occurs in up to $70 \%$ of patients who require therapy for chronic renal failure although, inexplicably, it is uncommon in children. The condition has an unexplained male predominance, and has a varied course, both in progression and severity. ${ }^{34}$ The classic uraemic neuropathy is distal, sensory, and motor, and predominantly axonal. Burning sensations in the feet, or band-like sensations may be early sensory features, whereas weakness of foot dorsiflexion is usually the first motor complaint. Loss of the ankle jerk and impaired vibration sense in the feet are frequent early signs of uraemic neuropathy. ${ }^{34}$ As the condition advances, wasting, weakness, and ascending sensory disturbance become more pronounced. Although usually sensory and motor in type, cases of either pure sensory or pure motor uraemic neuropathy have been reported.

Isolated mononeuropathies, particularly carpal tunnel syndrome, are also common in the uraemic state. These may be due to vascular steal syndromes from forearm access shunts in some cases. However, these neuropathies also occur in the non-haemodialysed patient and presumably reflect an increased susceptibility to pressure palsies, due to a subclinical neuropathy. ${ }^{34}$

The vestibulocochlear nerve is the most commonly affected cranial nerve in uraemia. ${ }^{24}$ Variable hearing loss and occasionally complete deafness are reported, which may reverse with dialysis or renal transplantation. Uraemia related hearing deficits must be distinguished from the ototoxic effects of aminoglycoside antibiotics and other drugs, as well as conditions associated with hereditary hearing loss and nephropathy.

Investigation of uraemic neuropathy Although serum creatinine and urea concentrations generally correlate poorly with the 
degree of clinical involvement, if the degree of neuropathy is markedly out of proportion to the level of renal impairment, this should lead to a search for coexisting causes of neuropathy. Despite the pathology of uraemic neuropathy (see below), a slowing of proximal nerve conduction is the earliest neurophysiological finding, and may occur in the absence of a clinically evident neuropathy. ${ }^{33}$ Subsequently, as axonal loss and secondary demyelination occur, there is a decline in both conduction velocity and nerve action potential amplitude, which generally parallel the degree of clinical and pathological impairment. The CSF is rarely abnormal in uraemic neuropathy, unless there is concomitant encephalopathy (see above).

\section{Pathophysiology of uraemic neuropathy}

The condition has a predilection for large diameter axons, with relative sparing of the unmyelinated and small myelinated afferent neurons. There is a marked loss of axons and fibre breakdown in the distal nerve trunks of the legs with less severe changes proximally, normal spinal roots, and degeneration in the cervical portion of the dorsal columns. Anterior horn cells are intact but may show chromatolytic changes. Paranodal demyelination and separation of the myelin sheath from the axolemma are also found, but are considered to be secondary to the primary axonal damage. ${ }^{33}$

Uraemic peripheral neuropathy does not develop if the glomerular filtration rate remains above about $12 \mathrm{ml} / \mathrm{min}$, whereas the neuropathy is reversed, at least partially, by dialysis and dramatically by renal transplantation. The so called "middle molecule hypothesis", with accumulation of one (or several) neurotoxic molecules of molecular weight 300-2000 Da which are slowly dialysable has been a popular explanation for the genesis of uraemic neuropathy. No one substance has yet been convincingly shown to have a close correlation among plasma and tissue concentrations and the severity of the polyneuropathy. Candidate compounds considered include guanidino compounds, polyamines, phenol derivatives, myoinositol, and parathyroid hormone. Enzyme inhibition by toxins has also been studied, particularly the enzymes transketolase, pyridoxal phosphate kinase, and sodiumpotassium ATP-ase. The aetiopathogenesis of the neuropathy may be multifactorial, explaining the apparent lack of correlation with any one variable. ${ }^{27} 35$

\section{Treatment of uraemic neuropathy}

Mild neuropathies may clinically resolve completely after dialysis is started, although impaired nerve conduction usually persists on neurophysiological testing. Severe cases slowly improve but do not fully recover, even after several years of dialysis. A few patients have been reported to have a paradoxical worsening of their neuropathy on commencing dialysis. Haemodialysis and continuous ambulatory peritoneal dialysis (CAPD) are both effective in preventing the progression of neuropathy, but CAPD may be the treatment of choice for patients with diabetes mellitus and end stage renal failure. ${ }^{33}$

Successful renal transplantation leads to a resolution of all but the most severe cases of neuropathy. Rapid recovery occurs in the first 3 months, followed by a slower phase over 9 months to 1 year. Sensory symptoms and signs disappear within days to weeks in many cases. Wasting and weakness are next to improve, with deep tendon reflexes recovering last of all. Uraemia related autonomic dysfunction and deafness are largely reversible within 2 years of transplantation. ${ }^{27}$

Myopathic disturbance in the uraemic state The clinical presentation of the myopathy associated with chronic renal failure is similar to that of primary hyperparathyroidism and osteomalacia. Proximal limb weakness and wasting occur, with bone pain and tenderness adding to the functional incapacity. In the absence of a peripheral neuropathy, the knee jerks are preserved or even brisk.

Serum creatine kinase concentrations are usually normal, and neurophysiological studies show a myopathic pattern without positive sharp waves or fibrillations. Muscle biopsy yields non-specific findings, with type 2 ("fast twitch") fibre atrophy. ${ }^{36}$

The myopathy associated with chronic renal failure results from a complex interaction of metabolic factors, including reduced levels of 1,25-dihydroxycholecalciferol, hypocalcaemia, hyperphosphataemia, and hyperparathyroidism. Parathyroid hormone enhances muscle proteolysis and impairs energy production, transfer, and utilisation. Vitamin D has been shown to influence muscle contractility in rodents, possibly via the calcium binding component of the troponin complex. The vitamin also accelerates protein synthesis and increases muscle ATP concentration. Some patients, but not all, with chronic renal impairment and myopathy respond to large doses of vitamin D.

Gangrenous calcification is a rare, but sometimes fatal, complication of chronic renal failure. In this condition there is ischaemia of skin and muscle due to a widespread deposition of calcium in the media and external elastic lamina of the arterial wall. A painful myopathy may ensue, with muscle necrosis and myoglobinuria. ${ }^{36}$

\section{Neurological complications associated with} dialysis

DIALYSIS DYSEQUILIBRIUM SYNDROME

Dialysis dysequilibrium syndrome (DDS) was first recognised in the 1960s when patients with severe uraemia were often rapidly dialysed over short periods of time. It may occur during or after peritoneal dialysis or haemodialysis. Children and elderly people have a higher risk of developing DDS than other age groups. In its mildest form DDS may comprise restlessness, muscle cramps, nausea, and severe headache. Patients with a history of migrainous type headaches may experience identical headaches during dialysis. Symptoms generally occur towards the end of dialysis and subside over 
several hours. ${ }^{24}{ }^{27} \mathrm{~A}$ more severe form of DDS is characterised by myoclonus and delirium which can persist for several days. The disease may also produce generalised seizures, papilloedema, raised intraocular pressure, and cardiac arrthymias. Such features are now extremely uncommon, with most deaths from DDS being reported before 1970. Today, if a patient undergoing dialysis were to become obtunded or comatose, DDS would be a diagnosis of exclusion, with other disorders, including intracranial bleeding and infection, being sought first. ${ }^{24}$

Dialysis dysequilibrium syndrome arises because of an osmotic gradient which develops between the plasma and brain during rapid dialysis. ${ }^{27}$ Arieff et al showed in uraemic dog model of dysequilibrium that an intracellular acidosis occurs in the brain in association with an increase in unmeasured organic acids. This generates an osmotic gradient and leads to a shift of water into the brain parenchyma, producing encephalopathy, raised intracranial pressure, and cerebral oedema. ${ }^{37}$

Prevention of DDS is largely achieved by "slow" dialysis - that is, low blood flow rates, at frequent intervals (every 1 to 2 days). A further measure includes the addition of an osmotically active solute (for example, urea, glycerol, mannitol, or sodium) to the dialysate.

WERNICKE'S ENCEPHALOPATHY

Although thiamine is a water soluble vitamin, and might therefore be expected to cross the dialysis membrane with ease, there have been only a few reports of Wernicke's encephalopathy in patients undergoing chronic dialysis. ${ }^{27} 3538$ In fact, the vitamin is not removed by dialysis to any greater degree than that which is normally excreted in urine. This may be due to the tight plasma protein binding of thiamine. The deficiency state probably only becomes manifest in special circumstances, such as a genetic predisposition, chronic malnourished patients with marked anorexia, and the use of glucose containing intravenous fluids. It also should be noted, however, that Wernicke's encephalopathy may not present in the classic way in chronic dialysis patients. Ophthalmoplegia was recorded in only one of five pathologically established cases in one series. Other diagnoses were considered in all five cases before death, including dialysis dementia, brainstem stroke, and uraemic encephalopathy. ${ }^{38}$ The disorder may therefore be underdiagnosed in patients undergoing dialysis.

\section{SUBDURAL HAEMATOMA}

Subdural haematomas have been reported in 1.0 to $3.3 \%$ of patients undergoing haemodialysis and all age ranges may be affected. Contributory factors are coagulation problems associated with the uraemic state, and the use of anticoagulants for dialysis. ${ }^{35} 39$ There is often no preceding history of trauma.

The clinical manifestations are protean and a high index of suspicion is necessary. The patient may be generally obtunded, cognitively impaired, and ataxic, with marked day to day fluctuations, or may display focal signs such as hemiparesis. Up to $20 \%$ of subdural haematomas are bilateral and may cause gait ignition failure and locomotor failure.

DIALYSIS DEMENTIA

Dialysis dementia (also known as dialysis encephalopathy, progressive myoclonic dialysis encephalopathy, and haemodialysis encephalopathy) was first clearly documented by Alfrey et al in 1972. ${ }^{40}$ The disorder is progressive, and invariably fatal unless treated. Dialysis dementia may be part of a multisystem disorder which includes vitamin $\mathrm{D}$ resistant osteomalacia, proximal myopathy, and noniron deficient, microcytic, hypochromic anaemia.

In Europe, between 1976 and 1977, the prevalence of dialysis dementia was 600 per 100000 dialysis patients, although there was a wide variation between centres (see below). The mean age of those affected in a large series was 50 years, with an age range of 21 to $68 .^{42}$ Mean onset of symptoms after haemodialysis had commenced was 35 months in the same series (range 0.5-112 months). Death occurred 6 to 9 months after the onset of symptoms in most untreated cases. The current prevalence of dialysis dementia has been estimated at around $0.6 \%$ to $1.0 \%$ of dialysis patients.

A mixed dysarthria and dysphasia with dysgraphia has been reported as one of the earliest signs of dialysis dementia in up to $95 \%$ of cases. The patient may initially have a stuttering, hesitant speech which only occurs during and immediately after dialysis. Initially the patient may also be more apathetic and become depressed. As the disorder progresses, language function becomes more severely and persistently involved. Myoclonic jerks occur in up to $80 \%$ of cases and patients may become both ataxic and dyspraxic. ${ }^{24} 27$

Convulsions develop in up to $60 \%$ in the later stages, and psychosis with hallucinations and paranoid delusions may be prominent. Frank dementia is obvious in over $95 \%$ of patients. Preterminally, the patient becomes immobile and mute. ${ }^{43}$

\section{Investigation of dialysis dementia}

Abnormalities in EEG may precede clinically overt symptoms by up to 6 months. Intermittent bursts of high voltage slowing and spike and wave activity are noted, particularly in the frontal leads. ${ }^{44}$ The EEG may show an initial deterioration after treatment with desferrioxamine has commenced (see below).

Neuroimaging studies and analysis of CSF are of no positive help in making the diagnosis of dialysis dementia but are of use in excluding other diagnoses if the clinical picture is atypical. The role of serum aluminium concentrations and the desferrioxamine infusion test are discussed briefly below.

\section{Pathophysiology of dialysis dementia}

An early finding was the marked geographical variation in the incidence of the dementia, suggesting the involvement of an environmental 
toxin. High concentrations of tin and decreased rubidium concentrations in the brains of patients with dialysis dementia were noted first. Subsequent work confirmed an 11-fold increased concentration of aluminium in the cerebral cortex of patients with dialysis dementia, compared with a threefold increase of nondemented dialysed patients. These findings were rapidly linked to the aluminium concentration in the dialysate water supply. ${ }^{27}{ }^{42}$ The European Dialysis and Transplant Association determined that $92 \%$ of cases of dialysis dementia were linked with untreated or "soft" water, compared with only $6 \%$ of cases who had received deionised water. It is now recognised that reducing concentrations of aluminium in water to below $20 \mu \mathrm{g} / 1$ by reverse osmosis seems to prevent the onset of the disease in patients who have just started dialysis. Sporadic cases of dementia still occur, however, and may relate in part to the use of phosphate binding gels such as aluminium hydroxide. Even absorption of $\mathrm{mg}$ via oral ingestion of these aluminium containing agents can lead to considerable accumulation of aluminium. However, as the use of these binders is so widespread, other, as yet unrecognised, factors must be involved, given the rarity of sporadic cases. ${ }^{24}{ }^{27}$

How aluminium interferes with neuronal function to cause the dementia, and why the transition between reversible and irreversible brain dysfunction occurs, is still unknown. Potential mechanisms include complexing with high energy phosphates, impaired enzymatic function, deoxyribonucleic acid binding, impaired hydrolysis of phosphoinositides, impaired microtubular function, reduced calmodulin activity via binding and reduced neurotransmitter uptake. Several of these mechanisms have only been demonstrated in in vitro models, and they are probably not mutually exclusive.

Neurofibrillary material has been found in cortical neurons of patients dying from dialysis dementia. There are, however, considerable differences both in the composition of the tangle material and its distribution compared with Alzheimer's disease.

Concentrations of aluminium in CSF are of no help in making the diagnosis of dialysis dementia. ${ }^{27}$ Serum aluminium concentrations are of only limited assistance: Dialysis dementia has been reported in patients with serum concentrations ranging from 15 to in excess of $1000 \mu \mathrm{g} / \mathrm{l}$ (normal range $<15 \mu \mathrm{g} / \mathrm{l}$ ). Although the dementia is uncommon with serum concentrations $<50 \mu \mathrm{g} / 1$, such concentrations by no means exclude the diagnosis. ${ }^{27}$

Desferrioxamine is a chelating agent which binds aluminium with greater affinity than that of the plasma proteins to which the metal is usually bound. The resulting desferrioxaminealuminium complex is removed by dialysis. The aluminium mobilised by desferrioxamine is an index of total body aluminium. The usual desferrioxamine chelation test protocol is to infuse $40 \mathrm{mg} / \mathrm{kg}$ of the drug over the last 30 minutes of a dialysis session. The change in serum aluminium concentration is measured between a baseline value and one taken 48 hours after dialysis. Increments varying between 100 and $200 \mu \mathrm{g} / 1$ have been described as the criterion for a positive test. The desferrioxamine chelation test has been used as an additional diagnostic test for dialysis dementia, but probably confers no advantage over and above baseline serum aluminium concentrations.

\section{Treatment of dialysis dementia}

The use of aluminium free dialysate may arrest, or even improve, the established case, but as aluminium is so avidly bound to plasma protein, very little is actually removed at subsequent dialyses. Desferrioxamine infusions are the mainstay of treatment of dialysis dementia, improving up to $70 \%$ of patients, sometimes to normal. Desferrioxamine binds aluminium with greater avidity than plasma protein and tissue binding sites. The chelated complex has a molecular weight of 600 and so is removed by dialysis. The clinical improvement is slow and therapy may need to be given once weekly for over a year. ${ }^{27}$ There is a similarity to chelation treatments used for other neurological illness (for example, D-penicillamine therapy for Wilson's disease) in that there may be a period of paradoxical clinical and EEG worsening after treatment is commenced. The mechanism for this is uncertain but the deterioration may be profound, and occasionally fatal.

\section{Neurological complications associated with renal transplantation}

More than 10000 renal transplants are now carried out worldwide each year, with an $85 \%$ to $95 \% 1$ year graft survival. About $30 \%$ of transplant recipients will develop neurological complications, although this figure may be higher if minor drug related side effects are also included. ${ }^{45}$ Some of these are considered below.

COMPLICATIONS RELATED TO THE TRANSPLANT PROCEDURE

Around $5 \%$ of patients acquire peripheral nerve injuries during the transplant procedure, usually because of intraoperative compression by retractors. The femoral nerve and lateral cutaneous nerve of the thigh are most commonly affected. The injury is usually neuropraxic in type and prognosis for recovery is generally good. ${ }^{46}$

In some patients the caudal spinal cord is supplied by branches of the internal iliac arteries instead of the intercostal arteries. When the iliac artery is then used to supply blood to the allograft in these patients, spinal cord ischaemia may result. This most commonly produces a conus medullaris syndrome, with lower extremity pain and sensory abnormalities, sphincter disturbance, and mixed upper and lower motor neuron signs. ${ }^{46}$

DIRECT NEUROLOGICAL SIDE EFFECTS OF IMMUNOSUPPRESSIVE AGENTS

Side effects relating to immunosuppressive therapy, especially cyclosporine, are some of the most common neurological problems encountered in the transplant recipient. Many 
Table 4 Neurological side effects associated with immunosuppressive agents

\begin{tabular}{|c|c|}
\hline Drug & Complications ${ }^{\star}$ \\
\hline Cyclosporinet & $\begin{array}{l}\text { Tremor }(40 \%) \text {, encephalopathy }(5 \%) \text {, seizures }(2-6 \%) \text {, hemiparesis, } \\
\text { paraparesis, tetraparesis, predominantly sensory neuropathy }\end{array}$ \\
\hline Corticosteroids & $\begin{array}{l}\text { Proximal myopathy, anxiety and dysthymia, psychosis (3\%), "steroid } \\
\text { pseudorheumatism", and headache, fever, lethargy on withdrawal }\end{array}$ \\
\hline $\begin{array}{l}\text { OKT3 monoclonal } \\
\text { antibody }\end{array}$ & $\begin{array}{l}\text { Transient influenza-like symptoms }<24 \text { hours } \ddagger(>90 \%) \text {, aseptic } \\
\text { meningitis } 24-72 \text { hours } \ddagger(2-14 \%) \text {, encephalopathy } 1-4 \text { days } \ddagger(1-10 \%)\end{array}$ \\
\hline
\end{tabular}

are relatively minor, but others are more serious and should be recognised because they are reversible on reduction or cessation of treatment. Table 4 summarises the neurological complications caused by the immunosuppressive agents in common use.

Some $15 \%$ to $40 \%$ of patients receiving cyclosporine experience neurological side effects. ${ }^{45}$ Higher blood concentrations of cyclosporine are associated with an increased risk of complications, although the correlation is not a close one, and metabolites which are not assayed may also be important. Factors which may predispose towards cyclosporine neurotoxicity are previous cranial irradiation, hypocholesterolaemia, hypomagnesaemia, $\beta$-lactam antibiotic therapy, aluminium overload, high dose steroids, hypertension, and uraemia.

More recently, a reversible posterior leukoencephalopathy syndrome has been described in a heterogeneous group of patients, including those undergoing renal, liver, and bone marrow transplantation and immunosuppressive treatment with either tacrolimus (FK506) or cyclosporine. ${ }^{47}$ Abrupt increases in blood pressure are probably central in the pathophysiology of the condition, which presents with headaches, vomiting, confusion, seizures, cortical blindness, and other visual abnormalities. Brain MRI confirms extensive bilateral white matter abnormalities suggestive of oedema in the posterior regions of the cerebral hemispheres. Providing the syndrome is recognised, and appropriate antihypertensive treatment is instituted in combination with a reduction or withdrawal of the immunosuppressive agent, the outcome is excellent. Others have criticised the term "reversible posterior leukoencephalopathy syndrome", and have pointed out that the condition is clinically and radiographically similar to the previously well characterised disorders of hypertensive encephalopathy and cyclosporin induced neurotoxicity. ${ }^{48}$

REJECTION ENCEPHALOPATHY

This may be more common in young recipients of transplants. Over $80 \%$ of cases occur within 3 months of transplantation but cases have been reported up to 2 years after surgery. The syndrome most commonly presents with convulsions, confusion, and headache, combined with systemic features of graft rejection. The EEG, neuroimaging, and CSF findings are non-specific. The release of cytokines in the rejection process may be important in the pathophysiology of this condition. Symptomatic treatment of the seizures is usually

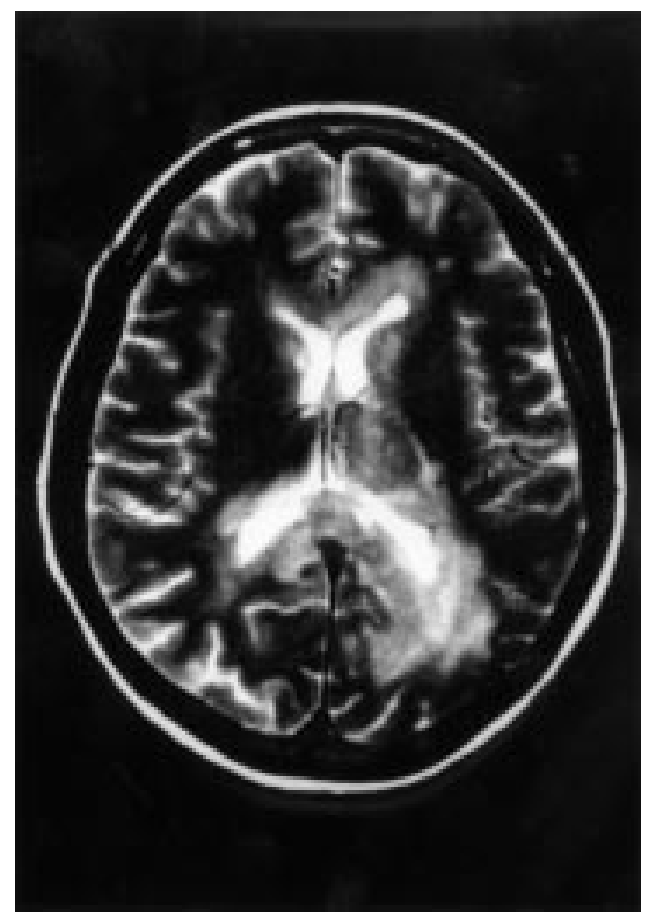

Figure $2 T 2$ weighted brain MRI, axial section, showing a case of primary lymphoma with predilection for the periventricular region.

necessary, but the prognosis overall is good for complete recovery. ${ }^{45}$

CENTRAL NERVOUS SYSTEM INFECTIONS

Renal transplant recipients are predisposed towards developing CNS infection primarily because of drug induced suppression of cell mediated immunity. Other predisposing factors include uraemia, hyperglycaemia, and indwelling catheters. Infections of the CNS, often fungal in type, have been reported in up to $45 \%$ of transplant patients coming to postmortem..$^{35}$

The timing of the infection after transplantation may give a clue to the nature of the likely pathogens. Broadly speaking, three phases exist. ${ }^{45}$ In the first of these, the first month after transplantation, CNS infection is actually very uncommon. When it does occur, infection is usually either acquired from the donor kidney, is related to the surgical procedure itself, or was present before transplantation. Pathogens are typically those found in the general, nonimmunosuppressed population.

The second phase extends from 1 to 6 months after transplantation. A combination of immunosuppressive drugs and the immunomodulating effect of common viruses means that immunosuppression is at its peak and the risk of CNS infection is greatest. Viruses (especially cytomegalovirus (CMV) and Epstein-Barr virus (EBV)) and opportunistic organisms (especially Aspergillus fumigatus, Nocardia asteroides, and Listeria monocytogenes) predominate.

The third phase of risk extends beyond 6 months after transplantation has occurred. Infections at this stage are either due to the lingering effects of previously acquired infections (such as CMV retinitis, for example), opportunistic infections in those patients who have 
often received higher than average immunosuppressive regimens because of chronic rejection (Nocardia asteroides, Cryptococcus neoformans, and Listeria monocytogenes are the most common organisms), or due to the return of a pattern of infection seen in nonimmunosuppressed subjects. ${ }^{45}$

Infections of the CNS in patients who have received a renal transplant may be difficult to diagnose, primarily due to an attenuation of the normal inflammatory response to infection. A high index of suspicion is therefore needed. In cryptococcal meningitis, for example, headache may precede the presence of obvious signs by days or weeks. Visual loss may be a relatively early feature due to optic nerve involvement and frank neck stiffness occurs late in the clinical course in many patients. Neuroimaging, followed by lumbar puncture (assuming no intracranial mass effect), is obligatory. The CSF analysis should include viral titres, fungal studies, and acid fast stain, as well as culture for Mycobacterium tuberculosis. Other tests, including polymerase chain reaction assays for JC virus (associated with progressive multifocal leucoencephalopathy) and fragments of $\mathrm{Myco}-$ bacterial DNA, may add to the diagnostic yield from lumbar puncture, but despite this, it is often not possible to make a definitive diagnosis in reasonable time, so empirical therapy must be started. Expert microbiological advice in these situations is vital, to ensure that the range of likely pathogens is covered with drugs that penetrate adequately into the CNS.

\section{POST-TRANSPLANT LYMPHOPROLIFERATIVE} DISORDER

Post-transplant lymphoproliferative disorder (PTLD) defines the range of abnormal proliferations of B lymphocytes which occur in renal transplant recipients. The range of disease, from benign diffuse polyclonal lymphoid hyperplasia to highly malignant monoclonal $\mathrm{B}$ cell lymphoma, is thought to be closely linked to EBV infection of B lymphocytes, and associated EBV driven lymphocyte proliferation. ${ }^{45}$

Primary CNS lymphoma is 35-fold more frequent in recipients of renal transplants than in normal subjects, and may develop as early as 3 months post-operatively. ${ }^{27}$ One third of lymphomas are multicentric and up to $40 \%$ involve the leptomeninges. ${ }^{49}$ They have a predilection for the periventricular or septal areas (fig 2). Brain CT or MRI may show a relatively large lesion, in comparison with the clinical status of the patient. Lesions are isodense or hypodense and enhance strongly after contrast is administered. Patients typically present with either features of raised intracranial pressure or disturbances of personality and memory. Seizures are uncommon because of the deepseated nature of the tumours. Brain biopsy is usually necessary to confirm the diagnosis. Malignant B cell lymphoma of the CNS in immunosuppressed patients carries a grave prognosis, and often responds poorly to chemotherapy and radiotherapy. ${ }^{45}$

\section{Conclusion}

This review illustrates how primary renal dysfunction may lead to a broad constellation of neurological symptoms and signs, and to highlight current pathophysiological views. Such a brief account cannot be comprehensive.

In addition, we have described some conditions, genetically determined and acquired, in which both the kidney and the nervous system may be affected by the disease process. Important advances have been made recently in our understanding of several of these conditions, particularly at the genetic and molecular concentrations.

The relatively recent introduction of renal replacement therapies and transplantation has led to a shift in emphasis in the type of neurological problem that may be encountered on a renal unit. The nature of the involvement of neurologists with their nephrology colleagues is likely to continue to evolve in the future as transplantation becomes more widespread, and the range of immunosuppressive agents available increases.

We are very grateful to Dr A Coulthard for providing the MRI images.

1 Maher ER, Yates JRW, Harries R, et al. Clinical features of on Hippel-Lindau disease. $Q \mathcal{F} \mathrm{Med}$ 1990;77:1151-63.

2 Filling-Katz MR, Choyke PL, Oldfield E, et al. Central nervous system involvement in von Hippel-Lindau disease. Neurology 1991;41:41-6.

3 Neurology 1991;41:41-6. Hippel-Lindau disease: genetic, clinical, and imaging features. Radiology 1995;194:629-42.

4 Latif F, Tory K, Gnarra J, et al. Identification of the von Hippel-Lindau disease tumor suppressor gene. Science 1993;260:1317-20.

5 Neumann HPH, Eggert HR, Weigel K, et al. Hemangioblastomas of the central nervous system: a 10-year study with special reference to von Hippel-Lindau disease. $\mathcal{F}$ Neurosurg 1989;70:24-30

6 Guay-Woodford LM, Muecher G, Hopkins SD, et al. The severe perinatal form of autosomal recessive polycystic kidney disease maps to chromosome $6 \mathrm{p} 21.1-\mathrm{p} 12$ : implications for genetic counselling. Am f Hum Genet 1995;56:1101-7.

7 Zerres K, Mucher G, Bachner L, et al. Mapping of the gene for autosomal recessive polycystic kidney disease to for autosomal recessive polycystic kidney disea

8 San Millan JL, Viribay M, Peral B, et al. Refining the localization of the PKD2 locus on chromosome 4q by linkage analysis in Spanish families with autosomal dominant polycystic kidney disease. Am f Hum Genet 1995;56:248-53.

9 Ong ACM. The polycystic kidney disease 1 (PKD-1) gene: an important clue in the study of renal cyst formation. $f R$ Coll Physicians Lond 1997;31:141-6.

10 Ravine D, Walker RG, Gibson RN, et al. Phenotype and genotype heterogeneity in autosomal dominant polycystic kidney disease. Lancet 1992;340:1330-3.

11 Ruggieri PM, Poulos N, Masaryk TJ, et al. Occult intracranial aneurysms in polycystic kidney disease: screening with MR angiography. Radiology 1994;191:33-9.

12 Chapman $\mathrm{AB}$, Rubinstein D, Hughes R, et al. Intracranial aneurysms in autosomal dominant polycystic kidney disease. N Engl f Med 1992;327:953-5.

13 Fehlings MG, Gentili F. The association between polycystic kidney disease and cerebral aneurysms. Can $\mathcal{F}$ Neurol Sci 1991;18:505-9.

14 Lozano AM, Leblanc R. Cerebral aneurysms and polycystic kidney disease: a critical review. Can 7 Neurol Sci 1992;19: $222-7$.

15 Ryu SJ. Intracranial haemorrhage in patients with polycystic kidney disease. Stroke 1990;21:291-4.

16 Pracyk JB, Massey JM. Moyamoya disease associated with polycystic kidney disease and eosinophilic granuloma. Stroke 1989;20:1092-4

7 Scelsi R, Verri AP, Bono G, et al. Familial amyloid polyneuropathy: report of an autopsy case with neuropathy, vitreous opacities and polycystic kidney. Eur Neurol 1989;29:27-32.

18 Hossack KF, Leddy CL, Johnson AM, et al. Echocardiographic findings in autosomal dominant polycystic kidney disease. N Engl F Med 1988;319:907-12.

19 Hoogenraad T. Wilson's disease. Major Problems in Neurology Series. London: Saunders, 1996;5:71-108.

20 Lyon G, Adams RD, Kolodny EH. Neurology of hereditary metabolic diseases of childhood, 2 nd ed. New York: McGrawmetabolic diseases of childh

21 Pollard JD, Young JAR. Neurology and the bone marrow. $\mathcal{F}$ Neurol Neurosurg Pyschiatry 1997;63:706-18. 
22 Moore PM, Richardson B. Neurology of the vasculitides and connective tissue diseases. F Neurol Neurosurg Pyschiaand connective tissue

23 Lockwood AH. Neurologic complications of renal disease. Neurol Clin 1989;7:617-27.

24 Fraser CL. Neurological manifestations of the uremic state. In: Arieff AI, Griggs RC, eds. Metabolic brain dysfunction in systemic disorders. Boston: Little Brown 1992:139-66.

25 Bolton CF, Young GB. Neurological complications of renal disease. Boston: Butterworths, 1990

26 Fraser CL, Arieff AI. Nervous system complications in uremia. Ann Intern Med 1988;109:143-53.

27 Raskin NH. Neurological aspects of renal failure. In Aminoff MJ, ed. Neurology and general medicine. 1st ed. New York: Churchill Livingstone, 1989;14:231-46.

28 Okada J, Yoshikawa K, Matsuo H, et al. Reversible MRI and CT findings in uremic encephalopathy. Neuroradiology 1991;33:524-6.

29 Guisado R, Arieff AI, Massry SG. Changes in the electroencephalogram in acute uremia: effects of parathyroid horcephalogram in acute uremia: effects of parathyroid ho-

30 Cogan MG, Covey CM, Arieff AI, et al. Central nervous system manifestations of hyperparathyroidism. Am $\mathcal{F ~ M e d ~}$ $1978 ; 65: 963-70$

31 Kerr DN, Ward MK, Ellis HA, et al. Aluminium intoxication in renal disease. Ciba Foundation Symposium 1992;169:123-35.

32 Candy JM, McArthur FK, Oakley AE, et al. Aluminium accumulation in relation to senile plaque and neurofibrillary tangle formation in the brains of patients with renal failure. F Neurol Sci 1992;107:210-8

33 Jennekens FGI. Peripheral neuropathy in renal and hepatic insufficiency. In: Matthews WB, ed. Handbook of clinical neurology. Vol 51. Neuropathies. Amsterdam: Elsevier 1987; 20:355-64.

34 Schaumburg $\mathrm{HH}$, Berger AR, Thomas PK. Uremic neuropathy. In: Disorders of peripheral nerves. 2nd ed. neuropathy. In: Disorders of peripheral

35 Raskin NH, Fishman RA. Neurologic disorders in renal failure II. N Engl f Med 1976;294:204-10.
36 Engel AG. Metabolic and endocrine myopathies. In: Walton J, ed. Disorders of voluntary muscle. 5th ed. Edinburgh: Churchill Livingstone, 1988;25:811-68.

37 Arieff AI, Guisado R, Massry SG, et al. Central nervous system $\mathrm{pH}$ in uremia and the effects of hemodialysis. $\mathcal{F}$ Clin Invest 1977;58:306-9.

38 Jagadha V, Deck JHN, Halliday WC, et al. Wernicke's encephalopathy in patients on peritoneal dialysis or hemodialysis. Ann Neurol 1987;21:78-84.

39 Leonard CD, Shapiro FL. Subdural hematoma in regularly hemodialyzed patients. Ann Intern Med 1975;82:650-78.

40 Alfrey AC, Mishell JM, Burks J, et al. Syndrome of dyspraxia and multifocal seizures associated with chronic hemodialysis. Trans Am Soc Artif Intern Organs 1972;18:257-61.

41 Alfrey AC, LeGendre GR, Kaehny WD. The dialysis encephalopathy syndrome: possible aluminium intoxication. N Engl F Med 1976;294:184-8.

42 Jack R, Rabin PL, McKinney TW. Dialysis encephalopathy: a review. Int f Psychiatry Med 1984;13:309-26.

43 Chokroverty S, Bruetman ME, Berger V, et al. Progressive dialytic encephalopathy. I Neurol Neurosurg Psychiatry 1976;39:411-19.

44 Hughes JR, Schreeder MT. EEG in dialysis encephalopathy. Neurology 1980;30:1148-54.

45 Patchell RA. Neurological complications of organ transplantation. Ann Neurol 1994;36:688-703.

46 Bruno A, Adams HP. Neurologic problems in renal transplant recipients. Neurol Clin 1988;6:305-25.

47 Hinchey J, Chaves C, Appignani B, et al. A reversible posterior leukoencephalopathy syndrome. $N$ Engl $f(\mathrm{Med}$ 1996;334:494-500.

48 Schwartz RB. A reversible posterior leukoencephalopathy syndrome. $N$ Engl f Med 1996;334:1743.

49 Balmaceda C, Gaynor JJ, Sun M, et al. Leptomeningeal tumor in primary central nervous system lymphoma: recognition, significance, and implications. Ann Neurol 1995;38:202-9. 